Article

\title{
Over-Expression of Semaphorin4D, Hypoxia-Inducible Factor-1 $\alpha$ and Vascular Endothelial Growth Factor Is Related to Poor Prognosis in Ovarian Epithelial Cancer
}

\author{
Ying Chen ${ }^{1}$, Lei Zhang ${ }^{1}$, Yi Pan ${ }^{2}$, Xiubao Ren ${ }^{3, *}$ and Quan Hao ${ }^{1, *}$ \\ 1 Department of Gynecologic Oncology, Tianjin Medical University Cancer Institute and Hospital, \\ Tianjin 300060, China; E-Mails: lychenying2004@hotmail.com (Y.C.); \\ zhanglei008_008@hotmail.com (L.Z.) \\ 2 Department of Pathology, Tianjin Medical University Cancer Institute and Hospital, \\ Tianjin 300060, China; E-Mail: panyi@hotmail.com \\ 3 Department of Biotherapy, Tianjin Medical University Cancer Institute and Hospital, \\ Tianjin 300060, China
}

* Authors to whom correspondence should be addressed; E-Mails: renxiubao@hotmail.com (X.R.); haoquandoctor@hotmail.com (Q.H.); Tel./Fax: +86-22-23340123 (ext. 3170) (X.R.); +86-22-23340123 (ext. 3120) (Q.H.).

Received: 20 August 2012; in revised form: 12 September 2012 / Accepted: 7 October 2012 / Published: 16 October 2012

\begin{abstract}
Semaphorin4D (SEMA4D) has been regarded as an important protein in tumor angiogenesis, though originally identified in neurodevelopment. SEMA4D is extensively expressed in several malignant solid tumors. Nevertheless, the function and expression of SEMA4D in epithelial ovarian cancer (EOC) is as yet not well understood. The aim of this study was to investigate SEMA4D expression in EOC and evaluate its clinical-pathological and prognostic significance. Immunohistochemistry was used to analyze SEMA4D expression and tumor angiogenesis-related proteins (HIF-1 $\alpha$ and VEGF) in tissues from 40 patients with normal ovarian epithelia and 124 EOC patients. SEMA4D was found to be expressed in $61.3 \%$ of the 124 EOC tissues, which was significantly higher than in the normal ovarian epithelia $(p<0.001)$. SEMA4D expression correlated with HIF-1 $\alpha$ and VEGF closely $(\rho=0.349$ and $0.263, p<0.001)$. Positive SEMA4D staining was significantly higher in tissues from patients with low histological grade, FIGO stage III-IV, lymph node metastasis and residual disease $\geq 1 \mathrm{~cm}(p<0.05)$. In the Cox proportional hazard mode, SEMA4D expression and histologic grade were independent indicators of overall survival (OS) and progress-free survival (PFS) for EOC patients. These findings
\end{abstract}


suggest that the cooperation of SEMA4D, HIF-1 $\alpha$, and VEGF may indicate poor prognosis for patients with EOC, thereby demonstrating that SEMA4D and its role in angiogenesis in EOC warrants further study.

Keywords: Semaphorin4D; HIF-1; VEGF; ovarian cancer; prognosis

\section{Introduction}

Semaphorins are a large family of transmembrane or glycosylphosphatidylinositol-linked proteins, which are grouped into eight classes [1]. Initially, the function of semaphorins has been best described in the nervous system. Recently, studies proved semaphorins are important players during angiogenesis, as they regulate blood vessel growth and endothelial cell homing during vessel development [2]. Semaphorin4D (SEMA4D, also known as CD100), a member of the semaphorin IV subfamily, has been found to promote angiogenesis upon binding its receptor Plexin-B1 both in vitro and in vivo $[3,4]$.

Angiogenesis is essential for the growth, invasion, and metastasis of tumors [5]. Hypoxia-inducible factor-1 (HIF-1) is a major regulator of cell adaptation to hypoxic stress and plays a critical role in tumorigenesis and angiogenesis [6]. HIF-1 is a heterodimer composed of two subunits: HIF-1 $\alpha$ and HIF-1 $\beta$. HIF- $1 \alpha$ is the oxygen-regulated subunit that determines HIF-1 activity. Under hypoxic conditions, HIF-1 transcriptional activity increases rapidly due to HIF-1 $\alpha$ protein over-expression [7]. HIF-1 binds to hypoxia response elements (HRE) in the promoter of target genes and activates their expression to mediate adaptive responses to decreased oxygen concentration, such as the formation of new blood vessels via proliferation and migration of endothelial cells toward the developing tumor [8]. This response is influenced by increased production of pro-angiogenic proteins such as vascular endothelial growth factor (VEGF). Moreover, like other pro-angiogenic factors, semaphorins may be regulated by changes in oxygen tension [9].

A recent study indicated that SEMA4D is induced by hypoxia in a HIF-1 dependent manner and influences tumor vascularity in head and neck squamous cell carcinoma (HNSCC) [10] in a manner analogous to VEGF in order to attract Plexin-B1-expressing endothelial cells into the tumor for the purpose of promoting growth and vascularity. It also demonstrated that SEMA4D cooperated with VEGF to promote angiogenesis [11]. Complementally, SEMA4D, which is under the control of the HIF-family of transcription factors, cooperates with VEGF to promote tumor growth and vascularity in oral squamous cell carcinoma [12].

Epithelial ovarian cancer (EOC) is the leading killer among all gynecological malignancies [13]. Tumor angiogenesis had been found to have important prognostic significance in advanced ovarian cancer [14]. However, the function and expression of SEMA4D in EOC is not very well understood. Here, we examine the expression of SEMA4D, HIF-1 $\alpha$ and VEGF in normal and cancerous ovarian tissues and assess their association with the established clinicopathologic factors of the disease as well as patient prognosis. 


\section{Results}

\subsection{Higher Expression of SEMA4D, HIF-1 $\alpha$ and VEGF in Ovarian Cancer than in Normal Ovarian Tissues}

Immunohistochemistry revealed that $61.3 \%(76 / 124), 41.9 \%(52 / 124)$ and $48.4 \%(60 / 124)$ of ovarian cancer tissues stained positively for SEMA4D, VEGF and HIF-1 $\alpha$, which were significantly higher than the positive staining in normal ovarian epithelial tissues $(61.3 \%$ vs. $10 \%, 41.9 \%$ vs. $10 \%$, and $48.4 \%$ vs. 5\%, $p<0.001$, respectively; Table 1). Figure 1 shows the representative immunohistochemistry results.

Table 1. SEMA4D, VEGF and HIF-1 $\alpha$ expressions in ovarian cancers and normal tissues.

\begin{tabular}{cccccccc}
\hline Group & $\begin{array}{c}\text { Cases } \\
(\boldsymbol{N})\end{array}$ & $\begin{array}{c}\text { SEMA4D positive } \\
\text { expression } \boldsymbol{n}(\boldsymbol{\%})\end{array}$ & $\boldsymbol{p}$ & $\begin{array}{c}\text { VEGF positive } \\
\text { expression } \boldsymbol{n}(\boldsymbol{\%})\end{array}$ & $\boldsymbol{p}$ & $\begin{array}{c}\text { HIF-1 } \boldsymbol{\alpha} \text { positive } \\
\text { expression } \boldsymbol{n}(\boldsymbol{\%})\end{array}$ & $\boldsymbol{p}$ \\
\hline EOC tissues & 124 & $76(61.3)$ & $<0.001$ & $52(41.9)$ & $<0.001$ & $60(48.4)$ & $<0.001$ \\
normal ovary & 40 & $4(10)$ & $4(10)$ & $2(5)$ & \\
\hline
\end{tabular}

\subsection{Positive Correlation between the Expression of SEMA4D and HIF-1 $\alpha$ or VEGF in Ovarian Cancer}

Among 76 EOC tissues stained positively for SEMA4D, 52.6\% (40/76) stained positively for VEGF and $63.2 \%$ (48/76) stained positively for HIF-1 $\alpha$. Likewise, among 60 EOC tissues stained positively for HIF-1 $\alpha, 65.0 \%$ (39/60) stained positively for VEGF. The correlation of SEMA4D, VEGF and HIF-1 $\alpha$ expression were closely $(\rho=0.263,0.349$ and $0.412, p<0.05$, respectively, see Table 2 ).

Table 2. Relationship of HIF-1 $\alpha$, VEGF and SEMA4D expression in EOC.

\begin{tabular}{|c|c|c|c|c|c|c|c|c|c|c|}
\hline & & \multirow[t]{2}{*}{$\begin{array}{c}\text { Cases } \\
(N)\end{array}$} & \multicolumn{2}{|c|}{$\begin{array}{c}\text { VEGF expression } \\
n(\%) \\
\end{array}$} & \multirow{2}{*}{$\begin{array}{c}\boldsymbol{\rho} \\
0.263\end{array}$} & \multirow{2}{*}{$\begin{array}{c}\boldsymbol{p} \\
0.002\end{array}$} & \multicolumn{2}{|c|}{$\begin{array}{c}\text { HIF-1 } \alpha \text { expression } \\
n(\%) \\
\end{array}$} & \multirow{2}{*}{$\begin{array}{c}\boldsymbol{\rho} \\
0.349\end{array}$} & \multirow{2}{*}{$\begin{array}{c}p \\
0.000\end{array}$} \\
\hline & & & Negative & Positive & & & Negative & Positive & & \\
\hline SEMA4D & Negative & 48 & $36(75.0)$ & $12(25.0)$ & & & $36(75.0)$ & $12(25.0)$ & & \\
\hline \multirow[t]{2}{*}{ expression $n(\%)$} & Positive & 76 & $36(47.4)$ & $40(52.6)$ & & & $28(36.8)$ & $48(63.2)$ & & \\
\hline & & & & & 0.412 & 0.000 & & & & \\
\hline HIF-1 $\alpha$ & Negative & 64 & $51(79.7)$ & $13(20.3)$ & & & & & & \\
\hline expression $n(\%)$ & Positive & 60 & $21(35.0)$ & $39(65.0)$ & & & & & & \\
\hline
\end{tabular}

\subsection{Expression of HIF-1 $\alpha$, VEGF and SEMA4D and Clinicopathologic Characteristics of EOC Patients}

As shown in Table 3, over-expressions of SEMA4D and HIF-1 $\alpha$ were closely related to EOC tissues with low histologic grade, advanced FIGO stage and lymph node (LN) metastasis $(p<0.05)$. Furthermore, over-expression of SEMA4D was also related to residual disease $\geq 1 \mathrm{~cm}$. Over-expression of VEGF was closely related to EOC tissues with low histologic grade, advanced FIGO stage, chemotherapy resistance, and platinum resistant and refractory $(p<0.05)$. These results suggest that over-expression of HIF-1, VEGF and SEMA4D are associated with a more malignant ovarian cancer phenotype. 
Figure 1. Representative images showing SEMA4D (A-F), VEGF (G-I) and HIF-1 $\alpha(\mathbf{J}-\mathbf{L})$ expressions. (A) SEMA4D negative expression in normal ovarian epithelia $(400 \times)$; (B) mucinous ovarian adenocarcinoma (G2) with negative immunostaining of SEMA4D (200×); (C) serous ovarian adenocarcinoma (G2, FIGO Stage II) with immunostaining of SEMA4D in the membrane of tumor cells (400×; Evaluation: 5 points); (D) serous ovarian adenocarcinoma (G3, FIGO Stage I) with immunostaining of SEMA4D (400×; Evaluation: 3 points); (E) endometrioid ovarian adenocarcinoma (G2, FIGO Stage III) with immunostaining of SEMA4D (400×; Evaluation: 6 points); (F) ovarian adenocarcinoma (G3 to undifferentiated, FIGO Stage III) with immunostaining of SEMA4D (400×; Evaluation: 7 points); (G) serous ovarian adenocarcinoma (G2, FIGO Stage I) with immunostaining of VEGF in the cytoplasm of tumor cells (400×; Evaluation: 2 points); (H) endometrioid ovarian adenocarcinoma (G2, FIGO Stage II) with immunostaining of VEGF in the cytoplasm of tumor cells (400×; Evaluation: 4 points); (I) endometrioid ovarian adenocarcinoma (G3, FIGO Stage IV) with immunostaining of VEGF (400×; Evaluation: 7 points); (J) serous ovarian adenocarcinoma (G2, FIGO Stage II) with immunostaining of HIF-1 $\alpha$ in the nuclei of tumor cells (400×; Evaluation: 1 point); (K) serous ovarian adenocarcinoma (G2, FIGO Stage III) with immunostaining of HIF-1 $\alpha$ (400×; Evaluation: 5 points); (L) ovarian adenocarcinoma (G3 to undifferentiated, FIGO Stage III) with immunostaining of HIF-1 $\alpha$ (400×; Evaluation: 7 points).

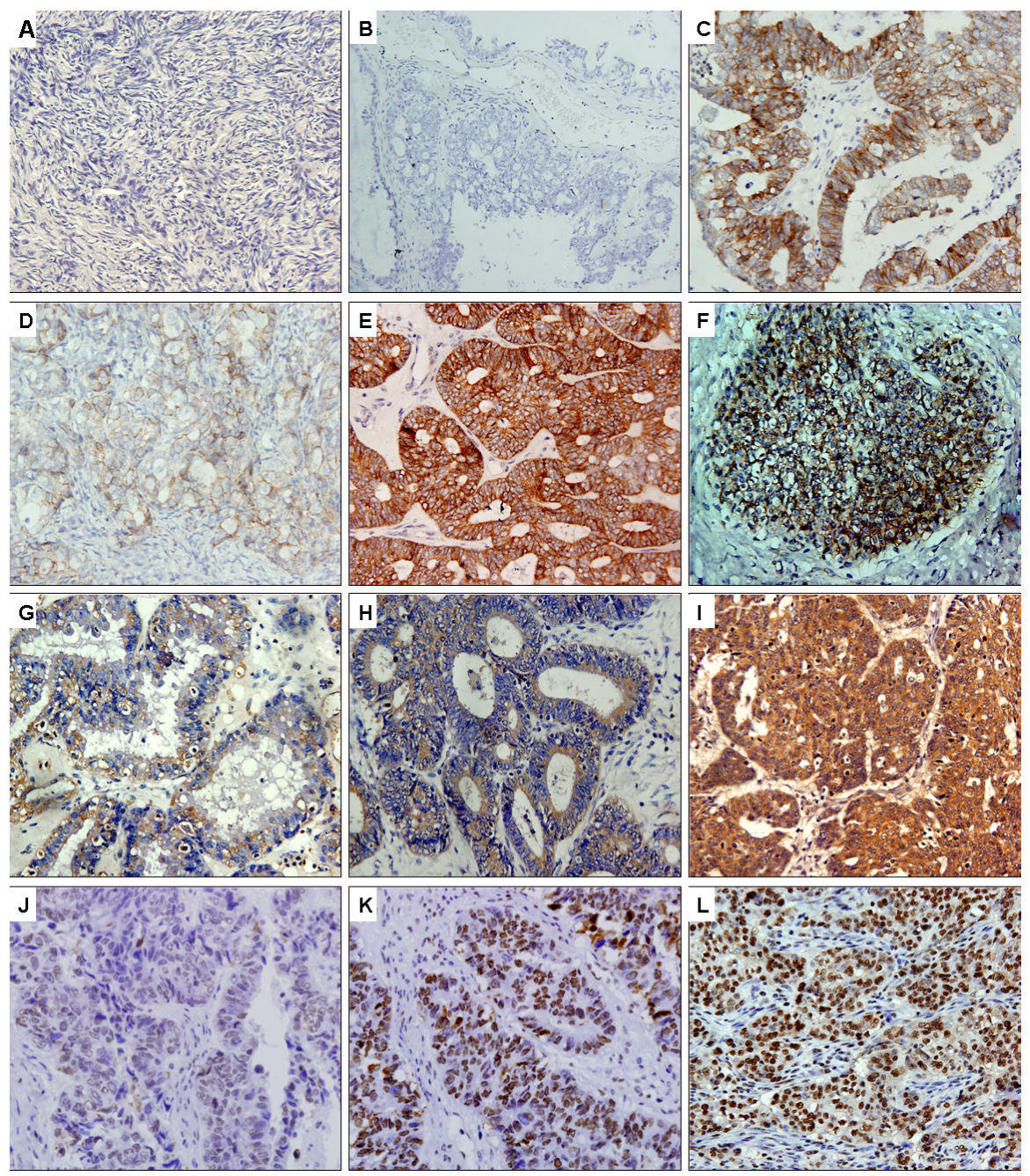


Table 3. Correlation between HIF-1 $\alpha$, VEGF and SEMA4D expressions with clinicopathologic characteristics of EOC patients.

\begin{tabular}{|c|c|c|c|c|c|c|c|}
\hline \multirow[t]{2}{*}{ Variable } & \multirow[t]{2}{*}{$\begin{array}{c}\text { Cases } \\
(N)\end{array}$} & \multicolumn{2}{|c|}{$\begin{array}{c}\text { SEMA4D positive } \\
\text { expression }\end{array}$} & \multicolumn{2}{|c|}{$\begin{array}{c}\text { VEGF positive } \\
\text { expression }\end{array}$} & \multicolumn{2}{|c|}{$\begin{array}{c}\text { HIF-1 } \alpha \text { positive } \\
\text { expression }\end{array}$} \\
\hline & & $n(\%)$ & $p$ & $n(\%)$ & $p$ & $n(\%)$ & $p$ \\
\hline Age & & & 0.078 & & 0.431 & & 0.276 \\
\hline$\leq 50$ years & 60 & $32(53.3)$ & & $23(38.3)$ & & $26(43.3)$ & \\
\hline$>50$ years & 64 & $44(68.8)$ & & $29(45.3)$ & & $34(53.1)$ & \\
\hline Menopausal status & & & 0.223 & & 0.913 & & 0.401 \\
\hline Yes & 78 & $51(65.4)$ & & $33(42.3)$ & & $40(51.3)$ & \\
\hline No & 46 & $25(54.3)$ & & $19(41.3)$ & & $20(43.5)$ & \\
\hline Pathologic type & & & 0.709 & & 0.581 & & 0.390 \\
\hline serous carcinoma & 80 & $50(62.5)$ & & $35(43.8)$ & & $41(51.3)$ & \\
\hline mucous and others & 44 & $26(59.1)$ & & $17(38.6)$ & & $19(43.2)$ & \\
\hline Histologic grade & & & 0.000 & & 0.039 & & 0.036 \\
\hline $\mathrm{G}_{1-2}$ & 49 & $20(40.8)$ & & $15(30.6)$ & & $18(36.7)$ & \\
\hline $\mathrm{G}_{3}$ or undifferentiated & 75 & $56(74.7)$ & & $37(49.3)$ & & $42(56.0)$ & \\
\hline FIGO Stage & & & 0.016 & & 0.000 & & 0.000 \\
\hline I-II & 53 & $26(49.1)$ & & $8(15.1)$ & & $16(30.2)$ & \\
\hline III-IV & 71 & $50(70.4)$ & & $44(62.0)$ & & $44(62.0)$ & \\
\hline LN metastasis & & & 0.017 & & 0.062 & & 0.000 \\
\hline No & 74 & $39(52.7)$ & & $26(35.1)$ & & $26(35.1)$ & \\
\hline Yes & 50 & $37(74.0)$ & & $26(52.0)$ & & $34(68.0)$ & \\
\hline Residual disease & & & 0.004 & & 0.304 & & 0.060 \\
\hline$<1 \mathrm{~cm}$ & 94 & $51(54.3)$ & & $37(39.4)$ & & $41(43.6)$ & \\
\hline$\geq 1 \mathrm{~cm}$ & 30 & $25(83.3)$ & & $15(50.0)$ & & $19(63.3)$ & \\
\hline $\begin{array}{l}\text { Patients' response to } \\
\text { chemotherapy }\end{array}$ & & & 0.349 & & 0.010 & & 0.108 \\
\hline $\mathrm{CR}$ & 87 & $51(58.6)$ & & $30(34.5)$ & & $38(43.7)$ & \\
\hline $\mathrm{PR}, \mathrm{SD}$ and $\mathrm{PD}$ & 37 & $25(67.6)$ & & $22(59.5)$ & & $22(59.5)$ & \\
\hline $\begin{array}{l}\text { Tumors' sensitivity to } \\
\text { chemotherapy }\end{array}$ & & & 0.315 & & 0.006 & & 0.149 \\
\hline Platinum sensitive & 92 & $54(58.7)$ & & $32(34.8)$ & & $41(44.6)$ & \\
\hline platinum resistant and refractory & 32 & $22(68.8)$ & & $20(62.5)$ & & $19(59.4)$ & \\
\hline
\end{tabular}

\subsection{Survival Analysis of Prognosis Factors in EOC}

In univariate analysis, the media of OS and PFS were associated with the histologic grade, FIGO stage, LN metastasis, residual disease, tumors' sensitivity to chemotherapy, response to chemotherapy, and expressions of HIF-1 $\alpha$ and SEMA4D $(p<0.05$, Table 4). Furthermore, as seen in Table 5, multivariate Cox analysis showed that advanced stage, low histologic grade and positive SEMA4D expression were the independent factors for evaluation of OS $(p<0.05)$. Additionally, low histologic grade and positive SEMA4D expression were the independent factors for evaluation of PFS $(p<0.05)$. Thus, patients with positive SEMA4D expression showed shorter OS and PFS than those with negative expression (Figure 2). 
Table 4. Univariate analysis of OS and PFS in EOC patients.

\begin{tabular}{|c|c|c|c|c|c|c|c|}
\hline Variable & $\operatorname{Cases}(N)$ & Media of OS & $\chi^{2}$ & $p$ & Media of PFS & $x^{2}$ & $p$ \\
\hline Age & & & 3.212 & 0.073 & & 1.830 & 0.176 \\
\hline$\leq 50$ years & 60 & 54 & & & 41 & & \\
\hline$>50$ years & 64 & 43 & & & 34 & & \\
\hline Menopausal status & & & 0.076 & 0.782 & & 0.069 & 0.793 \\
\hline Yes & 78 & 48 & & & & & \\
\hline No & 46 & 51 & & & & & \\
\hline Pathologic type & & & 0.354 & 0.552 & & 0.002 & 0.967 \\
\hline serous carcinoma & 80 & 43 & & & 41 & & \\
\hline mucous and others & 44 & 53 & & & 36 & & \\
\hline Histologic grade & & & 26.047 & 0.000 & & 5.636 & 0.018 \\
\hline $\mathrm{G}_{1-2}$ & 49 & 85 & & & 48 & & \\
\hline $\mathrm{G}_{3}$ or undifferentiated & 75 & 43 & & & 33 & & \\
\hline FIGO Stage & & & 32.221 & 0.000 & & 11.370 & 0.001 \\
\hline $\mathrm{I}-\mathrm{II}$ & 53 & 68 & & & 49 & & \\
\hline III-IV & 71 & 39 & & & 33 & & \\
\hline LN metastasis & & & 17.484 & 0.000 & & 12.361 & 0.000 \\
\hline No & 74 & 56 & & & 48 & & \\
\hline Yes & 50 & 35 & & & 33 & & \\
\hline Residual disease & & & 24.872 & 0.000 & & 5.824 & 0.016 \\
\hline$<1 \mathrm{~cm}$ & 94 & 54 & & & 41 & & \\
\hline$\geq 1 \mathrm{~cm}$ & 30 & 35 & & & 33 & & \\
\hline $\begin{array}{l}\text { Patients' response to } \\
\text { chemotherapy }\end{array}$ & & & 16.060 & 0.000 & & 5.393 & 0.020 \\
\hline $\mathrm{CR}$ & 87 & 53 & & & 40 & & \\
\hline $\mathrm{PR}, \mathrm{SD}$ and $\mathrm{PD}$ & 37 & 32 & & & 34 & & \\
\hline $\begin{array}{l}\text { Tumors' sensitivity to } \\
\text { chemotherapy }\end{array}$ & & & 10.502 & 0.001 & & 13.085 & 0.000 \\
\hline Platinum sensitive & 92 & 53 & & & 45 & & \\
\hline $\begin{array}{c}\text { platinum resistant and } \\
\text { refractory }\end{array}$ & 32 & 22 & & & 10 & & \\
\hline HIF-1 $\alpha$ & & & 25.811 & 0.000 & & 4.639 & 0.031 \\
\hline Negative & 64 & 59 & & & 41 & & \\
\hline Positive & 60 & 35 & & & 36 & & \\
\hline VEGF & & & 29.685 & 0.000 & & 1.945 & 0.163 \\
\hline Negative & 72 & 58 & & & 41 & & \\
\hline Positive & 52 & 32 & & & 34 & & \\
\hline SEMA4D & & & 34.933 & 0.000 & & 16.541 & 0.000 \\
\hline Negative & 48 & NR & & & 49 & & \\
\hline Positive & 76 & 41 & & & 31 & & \\
\hline
\end{tabular}

FIGO = International Federation of Gynecology and Obstetrics; $\mathrm{NR}=$ not reached; $\mathrm{CR}=$ complete response; $\mathrm{PR}=$ partial response; $\mathrm{SD}=$ stable disease; $\mathrm{PD}=$ progressive disease. 
Table 5. Multivariate analysis with regard to OS and PFS.

\begin{tabular}{|c|c|c|c|c|c|c|c|c|}
\hline \multirow[b]{3}{*}{ Variable } & \multicolumn{4}{|c|}{ Overall survival } & \multicolumn{4}{|c|}{ Disease-free survival } \\
\hline & \multirow[b]{2}{*}{$p$} & \multirow[b]{2}{*}{ HR } & \multicolumn{2}{|c|}{$95.0 \% \mathrm{CI}$} & \multirow[b]{2}{*}{$p$} & \multirow[b]{2}{*}{ HR } & \multicolumn{2}{|c|}{$95.0 \% \mathrm{CI}$} \\
\hline & & & Lower & Upper & & & Lower & Upper \\
\hline VEGF & 0.185 & 0.709 & 0.426 & 1.179 & & & & \\
\hline $\begin{array}{l}\text { Tumors' sensitivity to } \\
\text { chemotherapy }\end{array}$ & 0.053 & 0.493 & 0.241 & 1.009 & 0.104 & 0.566 & 0.286 & 1.123 \\
\hline $\begin{array}{l}\text { Patients' response to } \\
\text { chemotherapy }\end{array}$ & 0.392 & 0.735 & 0.363 & 1.488 & 0.392 & 0.735 & 0.363 & 1.488 \\
\hline FIGO Stage & 0.033 & 0.540 & 0.307 & 0.951 & 0.157 & 0.689 & 0.411 & 1.154 \\
\hline LN metastasis & 0.793 & 1.068 & 0.654 & 1.742 & 0.793 & 1.068 & 0.654 & 1.742 \\
\hline Histologic grade & 0.019 & 0.509 & 0.289 & 0.894 & 0.019 & 0.509 & 0.289 & 0.894 \\
\hline HIF- $1 \alpha$ & 0.113 & 0.671 & 0.409 & 1.099 & 0.113 & 0.671 & 0.409 & 1.099 \\
\hline SEMA4D & 0.001 & 0.395 & 0.225 & 0.691 & 0.012 & 0.507 & 0.299 & 0.859 \\
\hline Residual disease & 0.441 & 0.809 & 0.471 & 1.389 & 0.403 & 0.813 & 0.500 & 1.321 \\
\hline
\end{tabular}

Figure 2. Kaplan-Meier analysis for the disease-free survival and overall survival of epithelial ovarian cancer patients according to SEMA4D expression in cancer cells. The survival curves were analyzed by the log rank test. (A) Epithelial ovarian cancer patients with positive SEMA4D expression showed shorter progress-free survival than those with negative expression; (B) Epithelial ovarian cancer patients with positive SEMA4D expression showed shorter overall survival than those with negative expression.
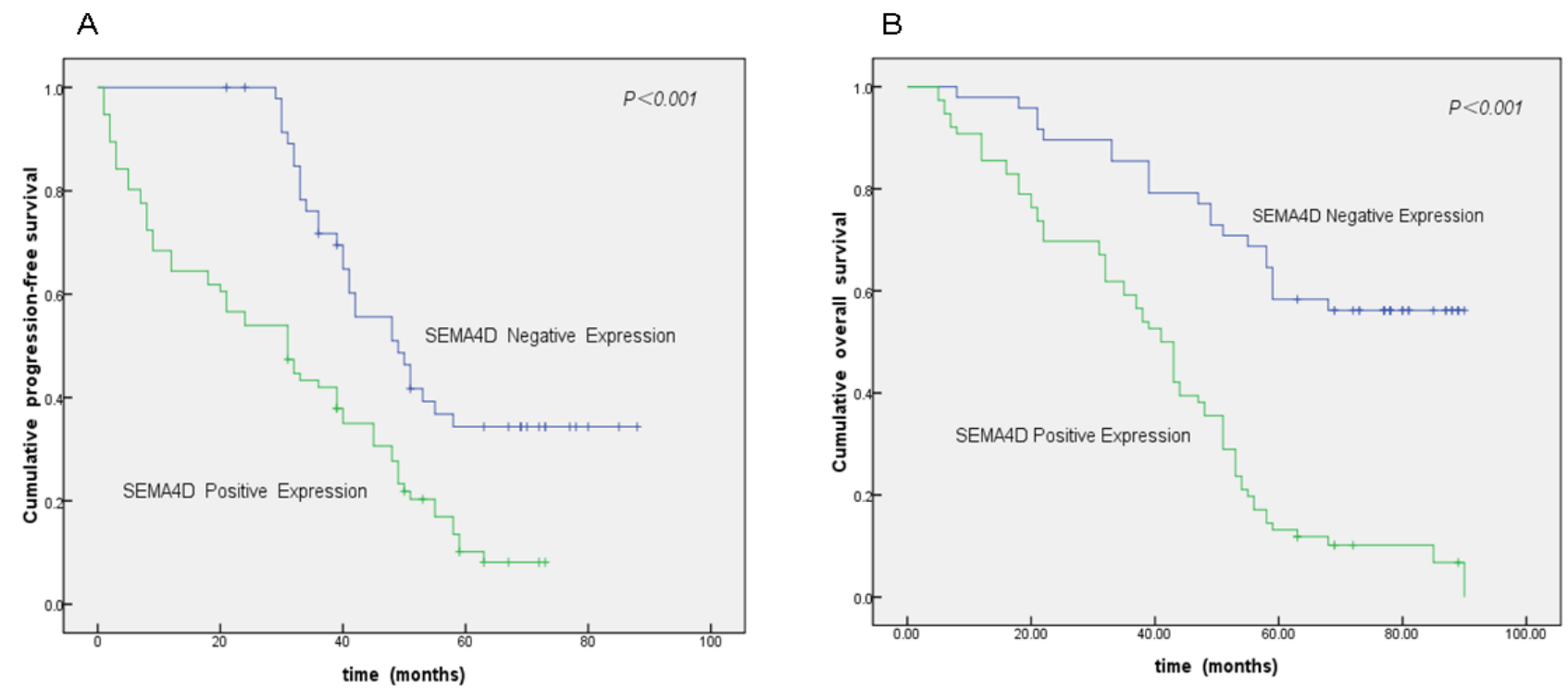

\section{Discussion}

There are striking similarities between the process of nerve growth and blood vessel branching [2]. SEMA4D, a protein originally shown to regulate axonal growth in the developing nervous system, has been identified as promoting angiogenesis in tumor progression.

Although SEMA4D has been previously explored in many types of cancer, including HNSCC, prostate cancer, colon cancer, breast cancer and lung cancer, its function remains unknown in ovarian 
cancer. In this study, data revealed SEMA4D positive expression in EOC tissues was obviously higher than in normal ovarian epithelial tissues.

The dimeric transcription factor HIF-1 is the key regulator of cellular response to hypoxia. HIF- $1 \alpha$ is the regulatory subunit of HIF-1 and determines its activity. The HIF-1 heterodimer binds to HREs in the cis-acting sequences of target genes including VEGF, which is involved in adaptive pathways like angiogenesis [15]. VEGF, a pro-angiogenic factor whose expression increases upon cellular exposure to low oxygen tension, plays a crucial role in stimulating the switch from a hypoxic, avascular phenotype to a pro-angiogenic phenotype in growing tumors [16]. In the present study, we also found the positive expressions of VEGF and HIF-1 $\alpha$ in EOC were significantly higher than in normal ovarian epithelial tissues.

Notably, previous studies had proved this angiogenic response elicited by SEMA4D was comparable to that by other well-known agiogenic molecules such as VEGF, HGF and bFGF and was dependent of up-regulation of these molecules [4,17]. HIF-1 $\alpha$ accumulates in the cytoplasm and is translocated to the nucleus to perform transcriptional activity, which includes inducing expression of its downstream signaling molecule VEGF [18]. In addition, Zhou et al. [11] examined the contribution of SEMA4D to tumor-induced angiogenesis when compared to VEGF and suggested that targeting these proteins might represent a complementary or parallel mode of treatment for anti-angiogenic therapy of HNSCC and other solid tumors exhibiting insensitivity of anti-VEGF therapy. Moreover, our results showed that SEMA4D expression was positively correlated with HIF-1 $\alpha$ and VEGF expression.

Furthermore, we found that over-expression of SEMA4D, VEGF and HIF-1 $\alpha$ were all closely related to low histologic grade and advanced stage, while indicating a shorter OS, which was partially consistent with a previous study that reported HIF-1 and VEGF were associated with poor prognosis of ovarian cancer patients [19]. We therefore hypothesize that SEMA4D may be another pro-angiogenic factor in the downstream signaling pathway of HIF-1 $\alpha$, though further studies are needed to test this hypothesis.

The next univariated and multivariate survival analysis showed that low histologic grade and SEMA4D over-expression were the independent factors for predicting OS and PFS of EOC patients. Similarly, recent work has revealed a correlation between high levels of SEMA4D expression in some sarcomas and poor overall patient prognosis [20]. Therefore, we speculate that SEMA4D inhibition might offer a promising target for tumor anti-angiogenesis therapy and prevention of metastatic progression and invasion in EOC.

\section{Experimental Section}

\subsection{Tissue Specimens}

A total of 40 normal ovarian epithelia and 124 EOC tissues were obtained from patients (median age: 40 years and 50 years, respectively) admitted at the Department of Gynecologic Oncology, Tianjin Medical University Cancer Institute and Hospital from January 2004 to December 2006. Normal ovarian tissues came from women who underwent surgery for benign or malignant gynecological diseases other than ovarian carcinoma. Tumor specimens were collected from women during primary surgery and prior to the initiation of adjuvant therapy. Approval by the Institutional 
Review Board of Tianjin Medical University Cancer Institute and Hospital was obtained in advance, and the informed consent requirement was waived because the current study was performed as a retrospective review. Adjuvant chemotherapy consisted of paclitaxel $\left(175 \mathrm{mg} / \mathrm{m}^{2}\right)$ and carboplatin $(6$ AUC) and no patient was treated with an anti-angiogenic therapy. All patients were followed until death or the end of the follow-up period (March 31, 2012).

\subsection{Immunohistochemical Staining}

Sections of 4-mm thick serially cut from formalin-fixed and paraffin-embedded tissue blocks were deparaffinized, rehydrated and autoclave-treated at $121^{\circ} \mathrm{C}$ for $10 \mathrm{~min}$ in $0.1 \mathrm{M}$ citrate buffer ( $\mathrm{pH} \mathrm{6.0)}$ to induce antigen retrieval. Endogenous peroxides in the section were blocked by incubation in 3\% hydrogen peroxide for $5 \mathrm{~min}$. Then, after being blocked with $0.5 \%$ goat serum for $60 \mathrm{~min}$, the sections were incubated at $4{ }^{\circ} \mathrm{C}$ overnight with HIF-1 $\alpha$ and VEGF primary antibodies (Santa Cruz Biotechnology Inc., Santa Cruz, CA, USA) or with SEMA4D (BD Biosciences, San Jose, CA, USA). The DAKO REAL EnVision Detection kit (DAKO) was subsequently applied for 30 min. Finally, sections were incubated in 3,3'-diaminobenzidine for $5 \mathrm{~min}$, followed by Mayer's hematoxylin counterstaining and mounting. Negative controls were obtained by replacing the primary antibody with isotype-matched monoclonal antibody. The percentage of positive cells was rated on the following point scale: no points (negative), $\leq 10 \%$ positive cells, regardless of staining intensity; 2 points, $11 \%-50 \%$ positive cells; 3 points, $51 \%-80 \%$ positive cells; and 4 points, $\geq 81 \%$ positive cells. The staining intensity was rated as follows: 1 point, weak intensity; 2 points, moderate intensity; and 3 points, strong intensity. Points for the percentage of positive cells and staining intensity were added, and specimens were attributed to two groups according to their overall score. Finally, specimens of $\leq 3$ points were rated as negative, or as positive [21]. Two independent investigators blinded to clinical data performed the analysis.

\subsection{Statistical Analysis}

The spearman rank correlation was used to assess the degree of correlation among variables. The survival rate was determined by the Kaplan-Meier method, and the log rank test was used to determine significance. Factors that were deemed of potential importance by univariate analysis were included in the multivariate analysis. A result was considered significant when the $p$ value was $<0.05$. All statistical analysis was performed with SPSS version 17.0 (SPSS Inc., Chicago, IL, USA).

\section{Conclusions}

In summary, we found SEMA4D expression was positively correlated with VEGF and HIF-1 $\alpha$ in EOC and was a novel indicator of poor prognosis for EOC patients. We expect that SEMA4D may serve as a reliable tool for early and accurate prediction of tumor recurrence and may be a potential therapeutic target for EOC patients. 


\section{References}

1. Sakurai, A.; Doçi, C.L.; Gutkind, J.S. Semaphorin signaling in angiogenesis, lymphangiogenesis and cancer. Cell Res. 2012, 22, 23-32.

2. Carmeliet, P.; Tessier-Lavigne, M. Common mechanisms of nerve and blood vessel wiring. Nature. 2005, 436, 193-200.

3. Basile, J.R.; Castilho, R.M.; Williams, V.P.; Gutkind, J.S. Semaphorin 4D provides a link between axon guidance processes and tumor-induced angiogenesis. Proc. Natl. Acad. Sci. USA 2006, 103, 9017-9022.

4. Conrotto, P.; Valdembri, D.; Corso, S.; Serini, G.; Tamagnone, L.; Comoglio, P.M.; Bussolino, F.; Giordano, S. Sema4D induces angiogenesis through Met recruitment by Plexin B1. Blood 2005, 105, 4321-4329.

5. Folkman, J. What is the evidence that tumors are angiogenesis dependent? J. Natl. Cancer Inst. 1990, 82, 4-6.

6. Lu, X.; Kang, Y. Hypoxia and hypoxia-inducible factors: Master regulators of metastasis. Clin. Cancer Res. 2010, 16, 5928-5935.

7. Wang, G.L.; Jiang, B.H.; Rue, E.A.; Semenza, G.L. Hypoxia-inducible factor 1 is a basic-helix-loophelix-PAS heterodimer regulated by cellular O2 tension. Proc. Natl. Acad. Sci. USA 1995, 92, 5510-5514.

8. Vajkoczy, P.; Farhadi, M.; Gaumann, A.; Heidenreich, R.; Erber, R.; Wunder, A.; Tonn, J.C.; Menger, M.D.; Breier, G. Microtumor growth initiates angiogenic sprouting with simultaneous expression of VEGF, VEGF receptor-2, and angiopoietin-2. J. Clin. Invest. 2002, 109, 777-785.

9. Siebold, C.; Berrow, N.; Walter, T.S.; Harlos, K.; Owens, R.J.; Stuart, D.I.; Terman, J.R.; Kolodkin, A.L.; Pasterkamp, R.J.; Jones, E.Y. High-resolution structure of the catalytic region of MICAL (molecule interacting with CasL), a multidomain flavoenzyme-signaling molecule. Proc. Natl. Acad. Sci. USA 2005, 102, 16836-16841.

10. Sun, Q.; Zhou, H.; Binmadi, N.O.; Basile, J.R. Hypoxia-inducible factor-1-mediated regulation of semaphorin 4D affects tumor growth and vascularity. J. Biol. Chem. 2009, 284, 32066-32074.

11. Zhou, H.; Binmadi, N.O.; Yang, Y.H.; Proia, P.; Basile, J.R. Semaphorin 4D cooperates with VEGF to promote angiogenesis and tumor progression. Angiogenesis 2012, 15, 391-407.

12. Zhou, H.; Yang, Y.H.; Binmadi, N.O.; Proia, P.; Basile, J.R. The hypoxia-inducible factor-responsive proteins semaphorin 4D and vascular endothelial growth factor promote tumor growth and angiogenesis in oral squamous cell carcinoma. Exp. Cell Res. 2012, 318, 1685-1698.

13. Ozols, R.F.; Bookman, M.A.; Connolly, D.C.; Daly, M.B.; Godwin, A.K.; Schilder, R.J.; Xu, X.; Hamilton, T.C. Focus on epithelial ovarian cancer. Cancer Cell 2004, 5, 19-24.

14. Sopo, M.; Anttila, M.; Sallinen, H.; Tuppurainen, L.; Laurema, A.; Laidinen, S.; Hamalainen, K.; Tuunanen, P.; Koponen, J.K.; Kosma, V.M.; et al. Antiangiogenic gene therapy with soluble VEGF-receptors $-1,-2$ and -3 together with paclitaxel prolongs survival of mice with human ovarian carcinoma. Int. J. Cancer 2012, 131, 2394-2401.

15. Semenza, G.L. Hypoxia-dinducible facor 1 (HIF-1) pathway. Sci. STKE 2007, 407, cm8. 
16. Neufeld, G.; Cohen, T.; Gengrinovitch, S.; Poltorak, Z. Vascular endothelial growth factor (VEGF) and its receptors. FASEB J. 1999, 13, 9-22.

17. Basile, J.R.; Barac, A.; Zhu, T.; Guan, K.L.; Gutkind, J.S. Class IV Semaphorins promote angiogenesis by stimulating Rho-initiated pathways through plexin-B. Cancer Res. 2004, 64, $5212-5224$.

18. Mizukami, Y.; Kohgo, Y.; Chung, D.C. Hypoxia inducible factor-1 independent pathways in tumor angiogenesis. Clin. Cancer Res. 2007, 13, 5670-5674.

19. Shimogai, R.; Kigawa, J.; Itamochi, H.; Iba, T.; Kanamori, Y.; Oishi, T.; Shimada, M.; Sato, S.; Kawaguchi, W.; Sato, S.; et al. Expression of hypoxia-inducible factor 1alpha gene affects the outcome in patients with ovarian cancer. Int. J. Gynecol. Cancer 2008, 18, 499-505.

20. Ch'ng, E.; Tomita, Y.; Zhang, B.; He, J.; Hoshida, Y.; Qiu, Y.; Morii, E.; Nakamichi, I.; Hamada, K.; Ueda, T.; et al. Prognostic significance of CD100 expression in soft tissue sarcoma. Cancer 2007, 110,164-172.

21. Bachtiary, B.; Schindl, M.; Pötter, R.; Dreier, B.; Knocke, T.H.; Hainfellner, J.A.; Horvat, R.; Birner, P. Cervical cancer prognosis in patients receiving radical radiotherapy for diminished response to radiotherapy and unfavorable over expression. Clin. Cancer Res. 2003, 9, 2234-2240.

(C) 2012 by the authors; licensee MDPI, Basel, Switzerland. This article is an open access article distributed under the terms and conditions of the Creative Commons Attribution license (http://creativecommons.org/licenses/by/3.0/). 